\title{
Understanding the Determinants of Weight-Related Quality of Life among Bariatric Surgery Candidates
}

\author{
Annie Tessier, ${ }^{1}$ Gerald S. Zavorsky, ${ }^{2,3}$ Do Jun Kim, ${ }^{1}$ Franco Carli, ${ }^{4}$ \\ Nicolas Christou, ${ }^{5}$ and Nancy E. Mayo ${ }^{1,6}$ \\ ${ }^{1}$ School of Physical and Occupational Therapy, McGill University Health Center, 3654 Promenade Sir William Osler, \\ Montreal, QC, Canada H3G 1V5 \\ ${ }^{2}$ Human Physiology Laboratory, Marywood University, Scranton, PA 18509, USA \\ ${ }^{3}$ The Commonwealth Medical College, Scranton, PA 18509, USA \\ ${ }^{4}$ Department of Anesthesia, Montreal General Hospital, McGill University Health Center, 1650 Cedar Avenue, \\ Room D10-144, Montreal, QC, Canada H3G 1A4 \\ ${ }^{5}$ Department of Surgery, Bariatric Clinic, Royal Victoria Hospital, McGill University Health Center, 687 Pine Avenue West, \\ Room S6.24, Montreal, QC, Canada H3A 1A1 \\ ${ }^{6}$ Division of Clinical Epidemiology, Royal Victoria Hospital, McGill University Health Center, 687 Pine Avenue West, \\ Ross 4.29, Montreal, QC, Canada H3A $1 A 1$
}

Correspondence should be addressed to Gerald S. Zavorsky, zavorsky@marywood.edu

Received 29 July 2011; Accepted 7 October 2011

Academic Editor: G. Silecchia

Copyright (C) 2012 Annie Tessier et al. This is an open access article distributed under the Creative Commons Attribution License, which permits unrestricted use, distribution, and reproduction in any medium, provided the original work is properly cited.

\begin{abstract}
Obesity and its relation to quality of life are multifaceted. The purpose of this paper was to contribute evidence to support a framework for understanding the impact of obesity on quality of life in 42 morbidly obese subjects considering a wide number of potential determinants. A model of weight-related quality of life (WRQL) was developed based on the Wilson-Cleary model, considering subjects' weight characteristics, arterial oxygen pressure $\left(\mathrm{PaO}_{2}\right)$, walking capacity (6-minute walk test, $\left.6 \mathrm{MWT}\right)$, healthrelated quality of life (HRQL; Physical and Mental Component Summaries of the SF-36 PCS/MCS), and WRQL. The model of WRQL was tested with linear regressions and a path analysis, which showed that as $\mathrm{PaO}_{2}$ at rest increased 6MWT increased. 6MWT was positively associated with the PCS, which in turn was positively related to WRQL along with the MCS. The model showed good fit and explained $38 \%$ of the variance in WRQL.
\end{abstract}

\section{Introduction}

The obesity epidemic currently facing the developed world $[1,2]$ is increasing the number of people affected by preventable causes of disability. This epidemic has an impact on the field of rehabilitation as interventions need to be adapted for people with obesity and new approaches need to be developed for people with disability resulting primarily from obesity.

Obesity can and does produce disability [3]. As reviewed elsewhere $[4,5]$, one physiological issue in the obese that is affected is the respiratory system. Some of the affected respiratory physiology includes altered static lung volumes, lower arterial oxygen pressure $\left(\mathrm{PaO}_{2}\right)$, increased alveolar-to- arterial oxygen pressure difference $\left(\mathrm{AaDO}_{2}\right)$ at rest, reduced respiratory system compliance with increased elastic loading of the inspiratory muscles, increased work and oxygen cost of breathing, and increased respiratory resistance compared to normal-weight individuals.

Nonetheless, obesity can affect almost all aspects of function and extend to impacting on quality of life (QOL) and health related quality of life (HRQL). The term "weight-related quality of life" (WRQL) is emerging to express the effect of excess weight on an individual's ability to live a fulfilling life [6].

The factors affecting the quality of life of obese people remain to be identified. Body mass index (BMI) explains only about one-third of the variance of WRQL $[7,8]$. Few 
nonmodifiable factors such as gender $[9,10]$, race $[8,9]$, and age $[10,11]$ have been associated with WRQL. Pain is known to have a strong impact on WRQL $[12,13]$. Other potentially modifiable predictors include depression, arthritis, and gastroesophageal reflux [14] along with weight-related stigma [15], but these factors are only a partial representation of the determinants of WRQL. Data also indicate that obese individuals with binge-eating disorder are strongly related to a poorer HRQL, whether these measures are evaluated in those without surgery [16] or postbariatric surgery [17]. However, it is not certain if binge-eating disorder independently affects WRQL. Modifiable factors such as cardiorespiratory fitness confers some HRQL benefits in the obese [18].

Measures of body size have been implicated with respiratory functions including $\mathrm{PaO}_{2}$ [19-21]. In earlier work on this same group of subjects, we showed that among people with morbid obesity, a high waist-to-hip ratio was associated with poorer arterial blood-gas status. On average, $\mathrm{PaO}_{2}$ decreases by $5 \mathrm{mmHg}$ and $\mathrm{AaDO}_{2}$ increases by $5 \mathrm{mmHg}$ as waist-to-hip ratio increases by 0.1 units [20, 21]. Gender plays a role in arterial blood-gas status, but that is only because the waist-to-hip ratio is different between males and females [22]. A recent review has shown that every 5 to $6 \mathrm{~kg}$ reduction in weight increases $\mathrm{PaO}_{2}$ by 1 and decreases $\mathrm{AaDO}_{2}$ by $1 \mathrm{mmHg}$ [5]. Waist circumference has also been associated with exercise capacity [23] and BMI has been associated with functional walking capacity as measured by the 6minute walk test (6MWT) (Pearson's $r=-0.71 ; P=0.002$ ) [24]. The demonstration that obese women have poorer walking capacities than normal-weight persons and that weight reduction improved walking speed and maximum oxygen uptake $\left(\mathrm{VO}_{2 \max }\right)$ supports a direct link between weight and mobility [25]. This relationship is likely mediated through respiratory function as research has shown a strong relationship between respiratory function and walking capacity ( $r=0.5$ to 0.8 between $\mathrm{VO}_{2 \max }$ and 6MWT) [26]. Walking capacity and $\mathrm{VO}_{2 \max }$ [18] have been found to relate to HRQL in obese people [27]. 6MWT correlated well (Spearman's rho: 0.39 to $0.49 ; P<0.01$ ) with the physical function domain of the Medical Outcome Study Short-Form Health Survey (SF-36) $[18,28]$, which is a well-established generic measure of HRQL. The fact that obese people report decrements up to $30 \%$ in most domains of the SF-36 relative to general population norms $[14,29,30]$ suggests that through some direct and/or indirect mechanisms, obesity impacts HRQL.

To do justice to the complexity of the relationships underlying WRQL requires a strong theoretical framework for estimating direct and indirect effects of these multiple constructs. In this study, the Wilson-Cleary was the theoretical model used to inform the statistical approach. The Wilson-Cleary model provides a conceptual model that encompasses HRQL and QOL [31]. This model proposes a linear relationship between biological and physiological factors, symptoms status, functional status, general health perception, and quality of life. In addition, characteristics of the individual and of the environment are included as mediating variables.
The aim of this study was to contribute evidence to support a framework for understanding the impact of obesity on quality of life, considering a wide number of potential determinants. The framework of WRQL was tested with linear regressions and a path analysis.

\section{Materials, Subjects, and Methods}

2.1. Participants. Morbidly obese persons scheduled for laparoscopic gastric bypass were recruited at the McGill University Health Center (MUHC), Montreal, Canada. They did not have (1) $\mathrm{BMI} \geq 75 \mathrm{~kg} / \mathrm{m}^{2}$, (2) a medical contraindication to exercise testing (acute myocardial infarction, cardiac arrhythmia, or use of pacemaker); (3) respiratory, renal, or hepatic failure; (4) metastatic disease; (5) cognitive impairment. All participants signed an informed consent form. The measures were collected at the time of their assessment. The study was approved by the MUHC institutional review board.

\subsection{Variables}

\subsubsection{Biological and Physiological Factors: Waist Circumference and $\mathrm{PaO}_{2}$ at Rest}

Arterial Blood Gases. Arterial blood gases were obtained from radial artery cannulation and sampled after 5 minutes of rest, with the participants sitting upright on a chair. The average of duplicate samples was recorded. Arterial bloodgases were corrected for changes in arterial blood temperature and measured directly via an ABL725 Blood Gas Analyzer (Radiometer, Copenhagen, Denmark). Details of the procedure are described elsewhere [21].

Aerobic Capacity Test. A test to determine peak oxygen uptake $\left(\mathrm{VO}_{2 \text { peak }}\right)$ was performed on an electrically braked cycle ergometer (Velotron Dynafit Pro, Racermate Inc., Seattle, WA). The $\mathrm{VO}_{2 \text { peak }}$ test commenced at $5 \mathrm{~W}$ and increased by $1 \mathrm{~W}$ every 2 to 6 seconds ( 10 to 30 watts every minute) until volitional exhaustion. The difference in the incremental increase in power output was to make sure all individuals fatigued within 8 to 12 minutes. $\mathrm{VO}_{2}$ was measured with a metabolic cart (model VMax 229LV, Sensorsmedics, Yorba Linda, CA) using the breath-by-breath option. The mean of the highest three consecutive $\mathrm{VO}_{2}$ values (averaged over 20second intervals) was defined as the $\mathrm{VO}_{2 \text { peak }}$.

2.2.2. Functional Walking Capacity: 6 MWT. 6MWT is the distance an individual can walk in 6-minutes; it reflects the capacity of an individual to perform daily activities. Typically, the distance walked by people with severe obesity revolves around 440-475 meters [32]. Predicted values for age and gender were estimated using the formula from Gibbons et al. [33].

2.2.3. Health Related Quality of Life: PCS and MCS. The SF36 is a 36-item survey that includes eight domains measuring physical functioning, role limitations due to physical health problems, bodily pain, general health perceptions, vitality, 
social functioning, role limitations due to emotional problems, and mental health. A physical and mental component summary (PCS and MCS) can be derived from these items. The summary scales are standardized with a mean of 50 and a standard deviation of ten [34]. The SF-36 is a reliable measure with good internal consistency and good test-retest reliability [35]. A factor analysis supported its construct validity [35]. Its convergent and discriminant validity have also been demonstrated [35]. Hopman et al. have developed Canadian norms for the SF-36 [36].

2.2.4. Weight-Related Quality of Life: IWQOL-Lite. The IWQOL-Lite is a self-reported questionnaire designed to assess the impact of obesity on quality of life. It is comprised of 31 items grouped into five dimensions: physical functioning, self-esteem, sexual life, public distress, and work. The measure provides scores for each separate dimension and a total score. The measure has excellent psychometric properties with good internal consistency (ranging from 0.90 to 0.96 ) [37], good test-retest reliability ( 0.83 to 0.94 ) [29], is sensitive to weight change $[38,39]$, and its scale structure is supported by confirmatory factor analysis [37]. To facilitate interpretation of values for the IWQOL-Lite, the scoring has been reversed and transformed according to the following formula:

Transformed score
$\quad=\left[\frac{(\text { maximum theoretical score }- \text { actual score })}{\text { test score range }}\right] \times 100$.

The score is considered as a continuous variable in the analysis.

2.3. Statistical Analysis. A model of WRQL was developed, based on the Wilson-Cleary model and existing evidence. The relationships between variables representing the different components within the Wilson-Cleary model were estimated with linear regressions. The statistical significance and the consistency with the literature in the direction of the coefficients were examined.

We further tested the model of WRQL with a path analysis. Path analysis allows the simultaneous estimation of all relationships between the variables in a single model rather than a series of models. It estimates the effect of each variable on the subsequent one, controlling for prior variables. A variable can be a dependent variable in one relationship and an independent variable in another. The several related relationships between biological, physiological, functional factors, and WRQL were modeled. We included variables that have been shown to have a significant impact on quality of life among people with obesity in previous studies. We used the software MPlus version 4 to confirm the model. The extent to which the data was consistent with the model was then tested with the maximum likelihood estimate method (ML). The full information maximum likelihood (FIML) estimation was used to impute data that were considered missing randomly. The latter is the recommended method as it yields consistent and efficient estimates [39]. To evaluate the fit of the model as a whole, few goodness-of-fit tests were used following the recommendations of $\mathrm{Hu}$ and Bentler [40] and Schermelleh-Engel et al. [41]. The goodness of fit tests assessed how the model accounts for the observed correlations or covariances. First, we used the chi-square test statistic, which should be close to zero [41]. As the chi-square test is highly dependent on sample size, other measures of fit were also used. The root mean square error of approximation (RMSEA) is a measure of approximate fit in the population and is concerned with the discrepancy due to approximation. Values less than 0.05 indicate good fit [41]. In addition, a $90 \%$ confidence interval (CI) enabled an assessment of the precision of RMSEA estimate. The lower boundary (left side) of the CI should contain zero for exact fit. RMSEA is regarded as relatively independent of sample size, and favors parsimonious models [41]. Another goodness-of-fit measure used was the standardized root mean square residual (SRMR), which is an overall fit measure based on residuals. A rule of thumb is that SRMR should be less than 0.05 for good fit. The comparative fit index (CFI) and the TuckerLewis index (TLI) are based on model comparisons. For both indexes, values greater than 0.97 indicate a good fit relative to the independent model. Because the TLI is not normed, values can be outside the range of 0 to 1 .

\section{Results}

Table 1 presents key characteristics of the 42 participants. Functional walking capacity (6MWT) was approximately $60 \%$ of age-predicted value. Aerobic capacity $(\mathrm{mL} / \mathrm{kg} / \mathrm{min})$ was below the 20th percentile. Values considerably lower than norms were reported for all subscales of the SF-36. Their HRQL scores, indicate impairment with the SF-36 physical component being more impacted than the mental component $(\mathrm{PCS}=34$; norm 52, MCS $=44$; norm 51) [36]. The sample had an average value of 46 out of 100 on the IWQOLLite. On the IWQOL-Lite, which has been transformed to have 100 indicating excellent quality of life, women reported much lower values than men, reaching statistical significance for overall quality of life, and for the dimensions of public distress and self-esteem. There were no major violations of the normality assumption. $4 \%$ of the data was missing with 6 out of 42 participants having 1 or more missing values.

The WRQL model consisted of the linear effect of waist circumference on $\mathrm{PaO}_{2}$ at rest, $\mathrm{PaO}_{2}$ at rest on $6 \mathrm{MWT}$, 6MWT on PCS, PCS on IWQOL-Lite, and MCS on IWQOLLite. Table 2 (Figure 2) presents univariate linear regression models. The relationships between each individual components of the WRQL model were statistically significant except for the effect of $\mathrm{PaO}_{2}$ at rest on 6MWT $(P=0.0546)$. Waist circumference was a predictor of $\mathrm{PaO}_{2}$ at rest, $\mathrm{PaO}_{2}$ at rest was a predictor of walking capacity, which in turn predicted PCS. Both PCS and MCS were predictors of IWQOL-Lite.

Four models were tested for each outcome. The first model estimated the effect of waist circumference on $\mathrm{PaO}_{2}$ at rest, the second model estimated the effect of waist circumference and $\mathrm{PaO}_{2}$ at rest on $6 \mathrm{MWT}$, the third estimated the effect of waist circumference, $\mathrm{PaO}_{2}$ at rest, and $6 \mathrm{MWT}$ on PCS, and finally the fourth estimated the effect of all 
TABLE 1: Characteristics of the study population by gender.

\begin{tabular}{|c|c|c|c|c|}
\hline & \multicolumn{2}{|c|}{$\operatorname{Men}(n=17)$} & \multicolumn{2}{|c|}{ Women $(n=25)$} \\
\hline & Mean & $\mathrm{SD}$ & Mean & $\mathrm{SD}$ \\
\hline \multicolumn{5}{|l|}{ Physiological variables } \\
\hline Age (years) & 43 & 8.9 & 38 & 10.2 \\
\hline Weight (kg) & 159 & 35.5 & $136^{*}$ & 19.0 \\
\hline Height (m) & 1.78 & 0.07 & $1.64^{*}$ & 0.07 \\
\hline BMI $\left(\mathrm{kg} / \mathrm{m}^{2}\right)$ & 50 & 9.8 & 51 & 6.7 \\
\hline Hip $(\mathrm{cm})$ & 140 & 19.2 & 147 & 12.7 \\
\hline Waist (cm) & 148 & 18.0 & $135^{*}$ & 14.5 \\
\hline Waist-to-hip ratio & 1.06 & 0.07 & $0.92^{*}$ & 0.08 \\
\hline $\mathrm{VO}_{2 \text { peak }}(\mathrm{mL} / \mathrm{kg} / \mathrm{min})($ fair $=38$ for males, 31 for females $)$ & 16.2 & $(4.9)$ & 14.4 & $(2.9)$ \\
\hline $\mathrm{VO}_{2 \text { peak }}(\mathrm{L} / \mathrm{min})$ & 2.58 & 0.78 & $1.96^{*}$ & 0.39 \\
\hline $\mathrm{VO}_{2}$ at rest $(\mathrm{L} / \mathrm{min})$ & 0.42 & 0.10 & $0.33^{*}$ & 0.06 \\
\hline $\mathrm{PaO}_{2}$ at rest $(\mathrm{mmHg})[99]$ & 83 & 11.3 & $91^{*}$ & 9.8 \\
\hline \multicolumn{5}{|l|}{ Functional status } \\
\hline $6 \mathrm{MWT}(\mathrm{M})$ & 429 & 110.5 & 414 & 83.3 \\
\hline \multicolumn{5}{|l|}{ SF-36 (0-100) } \\
\hline Physical functioning [86] & 32 & 27.8 & 43 & 24.2 \\
\hline Role physical [82] & 49 & 41.0 & 47 & 41.9 \\
\hline Bodily pain [76] & 52 & 28.4 & 45 & 23.9 \\
\hline GHP [77] & 43 & 13.8 & 41 & 19.5 \\
\hline Vitality [66] & 39 & 13.1 & 36 & 16.1 \\
\hline Social functioning [86] & 58 & 26.1 & 57 & 29.0 \\
\hline Role emotional [84] & 59 & 44.9 & 64 & 40.4 \\
\hline $\mathrm{MH}[78]$ & 63 & 17.5 & 60 & 19.4 \\
\hline PCS [51] & 35 & 11.3 & 33 & 9.8 \\
\hline MCS [52] & 44 & 9.8 & 44 & 9.9 \\
\hline \multicolumn{5}{|l|}{ Weight-related quality of life $(0-100)$} \\
\hline IWQOL overall & 55 & 24.7 & $40^{*}$ & 21.3 \\
\hline Public distress & 56 & 37.3 & $37^{*}$ & 20.5 \\
\hline Physical function & 45 & 25.0 & 36 & 16.1 \\
\hline Self-esteem & 49 & 29.1 & $24^{*}$ & 25.6 \\
\hline Sexual life & 46 & 21.0 & 35 & 28.7 \\
\hline Work & 45 & 22.9 & 36 & 22.6 \\
\hline
\end{tabular}

Abbreviations: BMI, body mass index; 6MWT, 6-minute walk test; MCS, mental component summary; PCS, physical component summary; MHI, Mental Health Index; GHP, general health perception; IWQOL, impact of weight on quality of life-lite. The parentheses in italic are norms for the SF-36 [36], and for $\mathrm{PaO}_{2}$ [42]. For $\mathrm{VO}_{2 \text { peak }}(\mathrm{mL} / \mathrm{kg} / \mathrm{min})$ the classification of "fair" is the 40th percentile value for age and gender from the American College of Sports Medicine [43]. Statistical difference between men and women, ${ }^{*} P$ value $<0.05,{ }^{*} P$ value $<0.0001$.

these factors together on IWQOL. Tables 3 and 5 shows the results of the multiple linear regression models, which were similar to those obtained from the univariate regression. The total variance of IWQOL-Lite explained by the model with waist circumference, $\mathrm{PaO}_{2}$ at rest, $6 \mathrm{MWT}$, PCS, and MCS was $28 \%$. These results show the limitations of regression as there is only one outcome variable and the predictors must act independently in order to have an effect. Numerous regressions need to be estimated to assess the relationship between several variables. In the multivariable model, each variable is adjusted for the effects of the others and hence their effects on other variables are not estimable.

A path Analysis was conducted (Table 4). A path coefficient $(\beta)$ represents the relative effect of each factor on subsequent factors, after controlling for all other prior and simultaneous effects. The path analysis supported the findings of the linear regression, all coefficients were statistically significant. The results of the path analysis are represented in Figure 1. According to the path analysis, as waist circumference increased, $\mathrm{PaO}_{2}$ at rest decreased $(\beta=$ $-0.234 ; P=0.0118)$. As $\mathrm{PaO}_{2}$ at rest increased, the distance walked in 6-minutes increased ( $\beta=2.585 ; P=0.0414)$. The $6 \mathrm{MWT}$ had a positive effect on physical functioning $(\beta=0.051 ; P=0.0008)$, which in turn was related to better quality of life $(\beta=1.148 ; P=<0.0001)$. Mental health was also associated with better IWQOL $(\beta=0.872 ; P=0.0052)$. The total effect of waist circumference on IWQOL-Lite was $-0.035[(-0.234) \cdot(2.585) \cdot(0.051) \cdot(1.148)]$. 


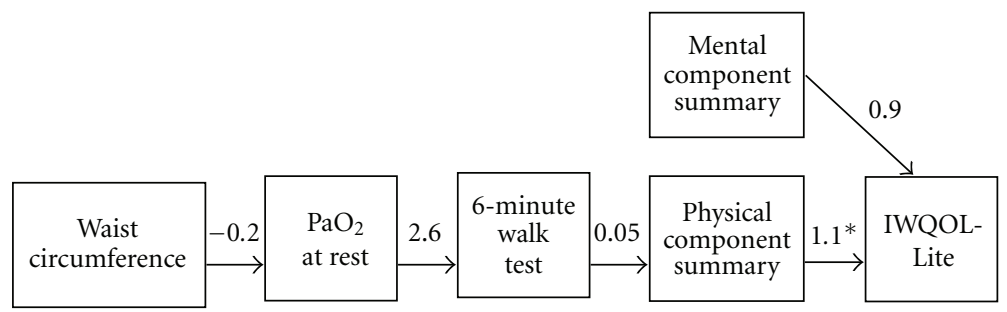

Figure 1: The path to quality of life for morbidly obese men and women. The coefficients correspond to the regression coefficient.

TABLE 2: Univariate linear regression models.

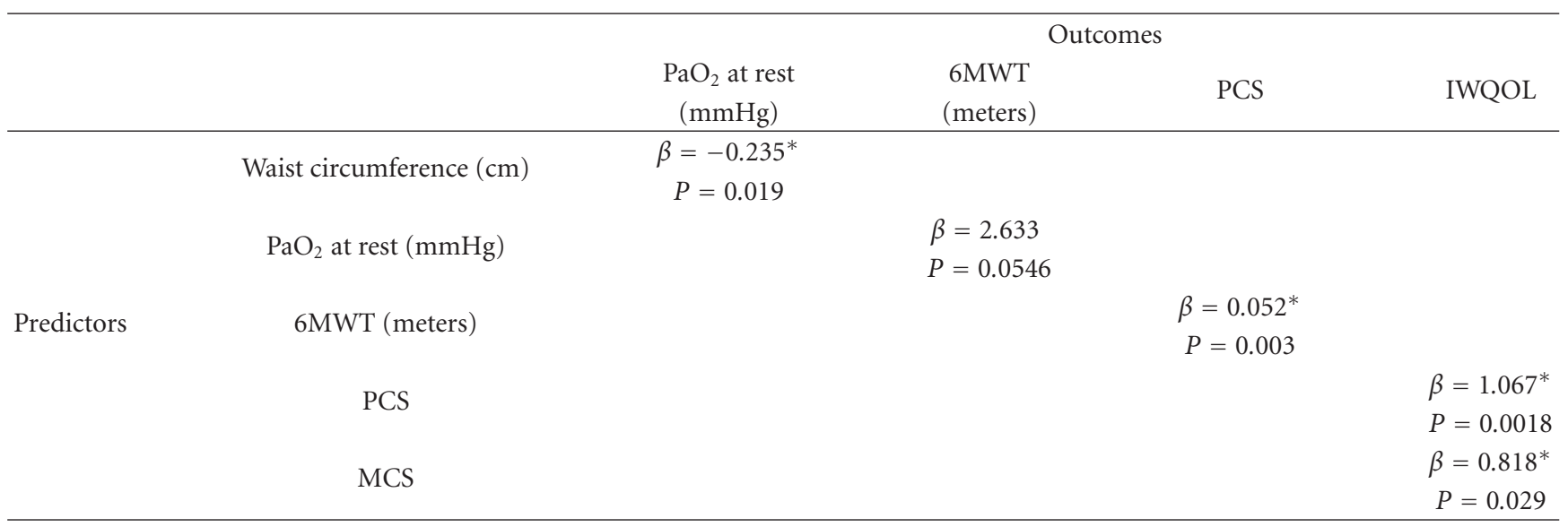

* Significant at $<0.05$.

TABLE 3: Multiple linear regression models.

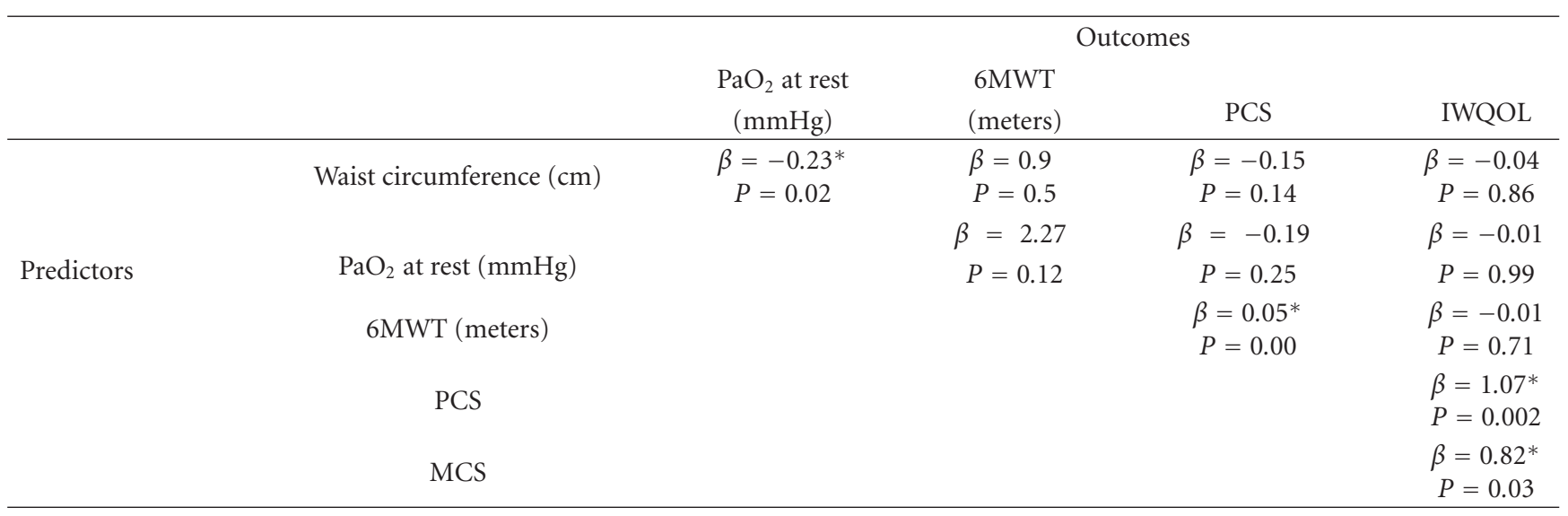

The effect of the predictors is estimated in four regression models for four different outcomes. ${ }^{*}$ Significant at $<0.05$.

The summary statistics suggested excellent fit of the data $\left(\chi^{2}=4.963,9 \mathrm{df}, P=0.838\right.$; RMSEA estimate $=0.000$, RMSEA 90\% confidence interval $=0.000-0.101$ SRMR $=$ $0.065 ; \mathrm{CFI}=1.000 ; \mathrm{TLI}=1.225$ ). The model explained $13 \%$ of the variance in $\mathrm{PaO}_{2}, 22 \%$ of PCS, 9\% of $6 \mathrm{MWT}$, and $38 \%$ of IWQOL-Lite.

\section{Discussion}

About $6 \%$ of Americans are morbidly obese [1] and a large proportion have impaired WRQL. Given the impact of obesity, the development of a framework for understanding and measuring the quality of life of people with obesity is essential. Understanding the determinants of WRQL could enable us to develop targeted biopsychosocial intervention to improve the quality of life of obese people. The interventions would then serve as a catalyst for engaging in behaviours which impact on both weight and on quality of life.

HRQL measures focus mainly on functioning, and fail to consider that people with chronic disease, such as obesity, may have adapted by finding alternative ways to have a satisfactory life. Some authors argue that we are really measuring perceived health and not HRQL with our present measures. That is, to assess HRQL adequately, the measures would have 


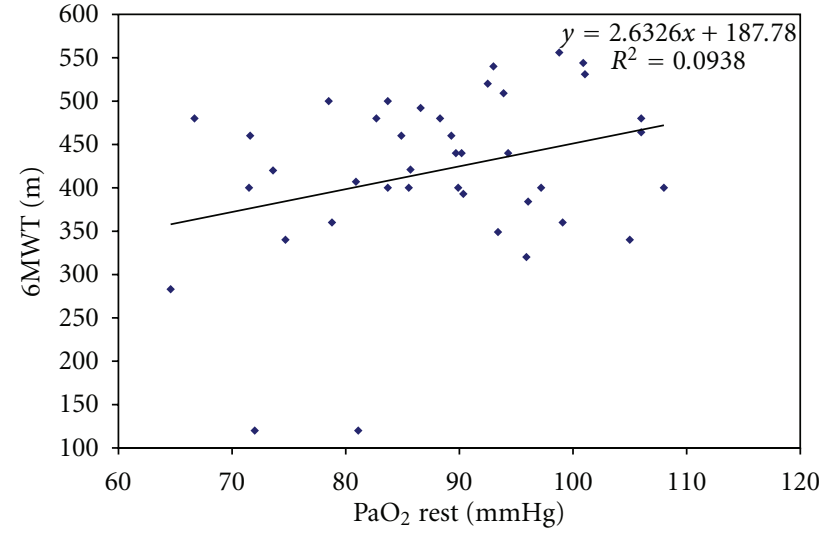

(a)

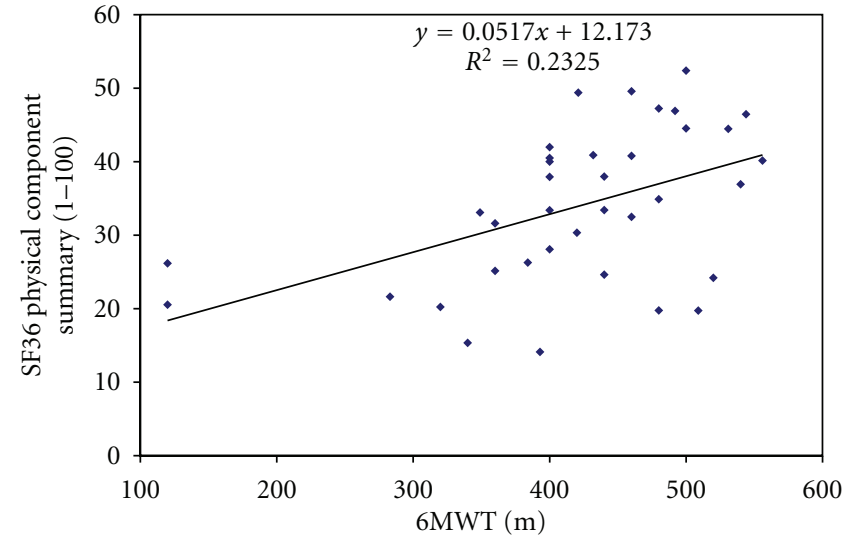

(b)

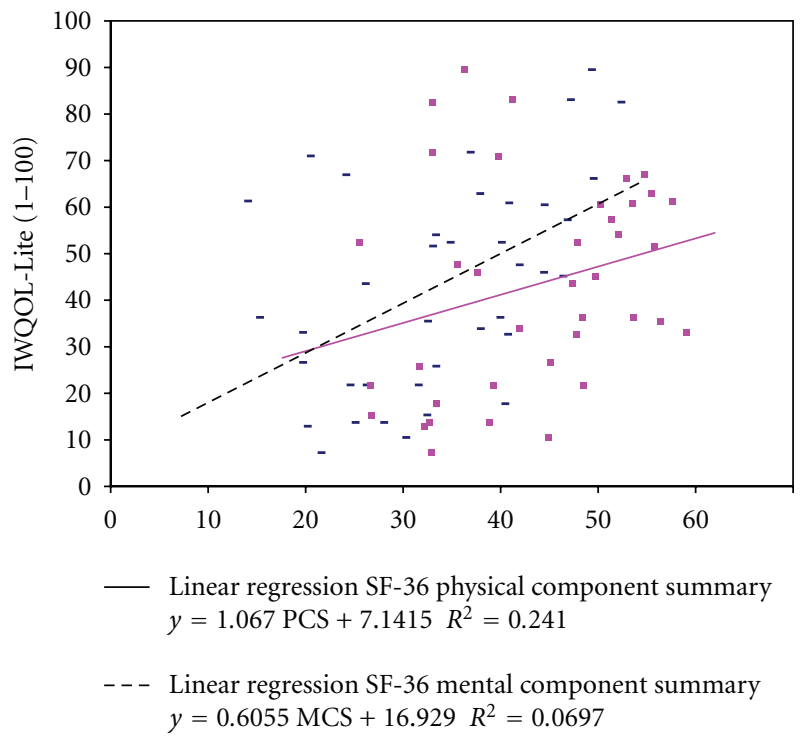

(c)

FIGURE 2: Univariate regressions: (a) relationship between $\mathrm{PaO}_{2}$ at rest and 6-minute walk test. (b) Relationship between 6-minute walk test and SF-36 Physical Component Summary. (c) In dashed line, the relationship between SF-36 Physical Component Summary (PCS) and IWQOL, and in solid line, the relationship between SF-36 Mental Component Summary (MCS) and IWQOL.

TABLE 4: Subpath estimates from the path analysis.

\begin{tabular}{lc}
\hline \multicolumn{3}{c}{ Estimate of effect } \\
\hline Waist $\rightarrow \mathrm{PaO}_{2}$ & \\
$\mathrm{PaO}_{2} \rightarrow$ 6MWT & $-0.234^{*}(0.093)$ \\
$6 \mathrm{MWT} \rightarrow$ PCS & $2.585^{*}(1.265)$ \\
$\mathrm{PCS} \rightarrow$ IWQOL & $0.051^{*}(0.015)$ \\
$\mathrm{MCS} \rightarrow$ IWQOL & $1.148^{*}(0.287)$ \\
\hline
\end{tabular}

The values are unstandardized beta coefficients and standard error in brackets.

to incorporate the values and meanings an individual places on a given function [44]. Our study may address this issue. Once the determinants of WRQL have been identified, they can be integrated in the measures of WRQL, which could improve their psychometric properties, and render them more reflective of patients' values rather than solely of their functioning.
The statistical significance of the relationships between the components of the model of WRQL was demonstrated with linear regression. Path analysis was used to further test the model. Path analysis is the optimal approach to test a model as it evaluates an entire hypothesized multivariate model. It allows for the estimation of the direct effect of a variable on another, as well as the indirect effect of a variable on another through an intervening variable. Consequently, path analysis has the capacity to assess complex models. The model revealed by the analysis is consistent with the theory and evidence. It supports the Wilson-Cleary conceptual model of HRQL. As shown here, the measures of body size were all highly correlated, but the model with waist size had the best fit. Based on correlations and regression models, waist-to-hip ratio has been found to predict $\mathrm{PaO}_{2}$, and an increase of waist-to-hip ratio is associated with lower resting $\mathrm{PaO}_{2}[20,21]$. PCS and MCS from the SF-36 can be considered as indicators of perceived health status, the 
TABLE 5: Univariate and multiple linear regression models to predict WRQL.

\begin{tabular}{lccc}
\hline & Beta coefficient & $P$ value & Adjusted $R^{2}$ \\
\hline Univariate linear regression & & & -0.411 \\
Waist circumference $(\mathrm{cm})$ & -0.180 & 0.869 & -0.008 \\
$\mathrm{PaO}_{2}$ at rest $(\mathrm{mmHg})$ & -0.057 & 0.224 & 0.013 \\
$6 \mathrm{MWT}$ (meters) & 0.049 & $0.002^{*}$ & 0.220 \\
$\mathrm{PCS}$ & 1.067 & $0.029^{*}$ & \\
$\mathrm{MCS}$ & 0.818 & & 0.101 \\
\hline Multiple linear regression & & 0.858 \\
Waist circumference $(\mathrm{cm})$ & -0.041 & 0.987 \\
$\mathrm{PaO}$ at rest (mmHg) & -0.006 & 0.712 \\
$6 \mathrm{MWT}$ (meters) & -0.015 & 0.005 \\
$\mathrm{PCS}$ & 1.122 & 0.015 \\
$\mathrm{MCS}$ & 0.918 & 0.275 \\
\hline $\mathrm{Abb}$
\end{tabular}

Abbreviations: $\mathrm{PaO}_{2}$, arterial blood gases at rest; 6MWT, 6-minute walk test; PCS, physical component summary; MCS, mental component summary.

* Significant at $<0.05$.

capacity to exercise should theoretically impact an individual's perceived health status. Both SF-36 and IWQOL-Lite are HRQL measures: one is generic while the other is obesity specific. Both measures are expected to be associated.

There are some limitations to our study. The analysis was conducted on a small sample size. The determination of the minimum sample size required in path analysis is complex. Unlike in a linear regression, where the sample size depends on the ratio of subjects to variables, in a path analysis it depends on the number of parameters to be estimated. There is little empirical basis for any particular recommendations. The model estimated is simple consisting of six variables and 5 paths (sample size of 42 for 13 free parameters). The variables are normally distributed, and there were no convergence problems or improper solutions, such as negative variance estimates or Heywood cases. There may be other valid alternative models, and some relationships may have been excluded from the model by lack of power, but the relationships included are undeniably significant. In addition, a path analysis (sometimes called causal modeling) tests theoretical propositions about cause and effect without manipulating variables. In this study the propositions are supported by this method of decomposing correlations but the result does not prove that the causal assumptions are correct. Therefore the results should be considered as preliminary and need to be cross-validated in other samples. The model explained $38 \%$ of the variance of IWQOL-Lite, which may appear small but can be expected considering the complexity of WRQL and the limited spectrum of variables available on this sample. The use of latent variable representing many observed indicators may help to explain more variance in future studies. Other variables such as weight history, readiness for change, and physical activity habits would be interesting to examine. Furthermore, the presence of binge-eating disorder was not evaluated, which could have affected the results. Finally, the analysis is based on the Wilson-Cleary model which proposes linear relationships between variables. This linear model may not be optimal to capture the network of factors around WRQL.
In conclusion, waist circumference, $\mathrm{PaO}_{2}$, functional walking capacity, and mental health were predictors of WRQL. Health professionals should address these factors.

\section{Disclosure}

The paper has not been published elsewhere and is not under simultaneous consideration by another journal. Previous reports of the same or very similar work has not been published. N. Christou is a consultant for Ethicon Endo-Surgery Inc. and has stock ownership in Weight Loss Surgery.

\section{Conflict of Interests}

The authors have no financial or other relationships that might lead to a conflict of interest, and the paper has been read and approved by all the authors.

\section{Acknowledgment}

Some funds for this paper were provided by the Quebec Health Research Foundation (Fonds de Recherche en Santé du Québec).

\section{References}

[1] K. M. Flegal, M. D. Carroll, C. L. Ogden, and L. R. Curtin, "Prevalence and trends in obesity among US adults, 19992008," Journal of the American Medical Association, vol. 303, no. 3, pp. 235-241, 2010.

[2] D. C. Lau, J. D. Douketis, K. M. Morrison, I. M. Hramiak, A. M. Sharma, and E. Ur, "2006 canadian clinical practice guidelines on the management and prevention of obesity in adults and children [summary]," Canadian Medical Association Journal, vol. 176, supplement 8, pp. S1-13, 2007.

[3] D. D. Hensrud and S. Klein, "Extreme obesity: a new medical crisis in the United States," Mayo Clinic Proceedings, vol. 81, supplement 10, pp. S5-S10, 2006.

[4] C. M. Salome, G. G. King, and N. Berend, "Physiology of obesity and effects on lung function," Journal of Applied Physiology, vol. 108, no. 1, pp. 206-211, 2010. 
[5] G. S. Zavorsky and S. L. Hoffman, "Pulmonary gas exchange in the morbidly obese," Obesity Reviews, vol. 9, no. 4, pp. 326$339,2008$.

[6] M. Bullinger, R. Anderson, D. Cella, and N. Aaronson, "Developing and evaluating cross-cultural instruments from minimum reqirements to optimal models," Quality of Life Research, vol. 2, no. 6, pp. 451-459, 1993.

[7] R. L. Kolotkin, E. C. Westman, T. Østbye, R. D. Crosby, H. J. Eisenson, and M. Binks, "Does binge eating disorder impact weight-related quality of life?" Obesity Research, vol. 12, no. 6, pp. 999-1005, 2004.

[8] R. L. Kolotkin, R. D. Crosby, and G. R. Williams, "Healthrelated quality of life varies among obese subgroups," Obesity Research, vol. 10, no. 8, pp. 748-756, 2002.

[9] M. A. White, P. M. O’Neil, R. L. Kolotkin, and T. K. Byrne, "Gender, race, and obesity-related quality of life at extreme levels of obesity," Obesity Research, vol. 12, no. 6, pp. 949-955, 2004.

[10] R. L. Kolotkin, S. Head, M. Hamilton, and C. K. Tse, "Assessing impact ofweight on quality of life," Obesity Research, vol. 3, no. 1, pp. 49-56, 1995.

[11] J. T. Fine, G. A. Colditz, E. H. Coakley et al., "A prospective study of weight change and health-related quality of life in women," Journal of the American Medical Association, vol. 282, no. 22, pp. 2136-2142, 1999.

[12] I. Barofsky, K. R. Fontaine, and L. J. Cheskin, "Pain in the obese: impact on health-related quality-of-life," Annals of Behavioral Medicine, vol. 19, no. 4, pp. 408-410, 1997.

[13] K. R. Fontaine, I. Barofsky, and L. J. Cheskin, "Predictors of quality of life for obese persons," Journal of Nervous and Mental Disease, vol. 185, no. 2, pp. 120-122, 1997.

[14] J. B. Dixon, M. E. Dixon, and P. E. O’Brien, "Quality of life after lap-band placement: influence of time, weight loss, and comorbidities," Obesity Research, vol. 9, no. 11, pp. 713-721, 2001.

[15] E. Y. Chen, L. E. Bocchieri-Ricciardi, D. Munoz et al., "Depressed mood in class III obesity predicted by weight-related stigma," Obesity Surgery, vol. 17, no. 5, pp. 669-671, 2007.

[16] M. Perez and C. S. Warren, "The relationship between quality of life, binge-eating disorder, and obesity status in an ethnically diverse sample," Obesity. In press.

[17] M. D. Kofman, M. R. Lent, and C. Swencionis, "Maladaptive eating patterns, quality of life, and weight outcomes following gastric bypass: results of an internet survey," Obesity, vol. 18, no. 10, pp. 1938-1943, 2010.

[18] R. L. Kolotkin, M. J. LaMonte, S. Litwin et al., "Cardiorespiratory fitness and health-related quality of life in bariatric surgery patients," Obesity Surgery, vol. 21, no. 4, pp. 457-464, 2010.

[19] S. Koziel, S. J. Ulijaszek, A. Szklarska, and T. Bielicki, "The effects of fatness and fat distribution on respiratory functions," Annals of Human Biology, vol. 34, no. 1, pp. 123-131, 2007.

[20] G. S. Zavorsky, J. M. Murias, D. J. Kim, J. Gow, J. L. Sylvestre, and N. V. Christou, "Waist-to-hip ratio is associated with pulmonary gas exhange in the morbidly obese," Chest, vol. 131, no. 2, pp. 362-367, 2007.

[21] G. S. Zavorsky, N. V. Christou, D. J. Kim, F. Carli, and N. E. Mayo, "Preoperative gender differences in pulmonary gas exchange in morbidly obese subjects," Obesity Surgery, vol. 18, no. 12, pp. 1587-1598, 2008.

[22] G. S. Zavorsky and B. Wilson, "Sex, girth, waists and hips (what matters for gas exchange in extreme obesity?)," Respiratory Physiology and Neurobiology, vol. 170, no. 1, pp. 120-122, 2010.
[23] P. M. Ribisl, W. Lang, S. A. Jaramillo et al., "Exercise capacity and cardiovascular/metabolic characteristics of overweight and obese individuals with type 2 diabetes: the look Ahead clinical trial," Diabetes Care, vol. 30, no. 10, pp. 2679-2684, 2007.

[24] M. Maniscalco, A. Zedda, C. Giardiello et al., "Effect of bariatric surgery on the six-minute walk test in severe uncomplicated obesity," Obesity Surgery, vol. 16, no. 7, pp. 836-841, 2006.

[25] U. E. Larsson and E. Mattsson, "Influence of weight loss programmes on walking speed and relative oxygen cost (\%VO2max) in obese women during walking," Journal of Rehabilitation Medicine, vol. 35, no. 2, pp. 91-97, 2003.

[26] R. A. Wise and C. D. Brown, "Minimal clinically important differences in the six-minute walk test and the incremental shuttle walking test," Journal of Chronic Obstructive Pulmonary Disease, vol. 2, no. 1, pp. 125-129, 2005.

[27] C. A. Piquette, L. Clarkson, K. Okamoto, J. S. Kim, and B. K. Rubin, "Respiratory-related quality of life: relation to pulmonary function, functional exercise capacity, and sputum biophysical properties," Journal of Aerosol Medicine, vol. 13, no. 3, pp. 263-272, 2000.

[28] K. Mannerkorpi, U. Svantesson, and C. Broberg, "Relationships between performance-based tests and patients' ratings of activity limitations, self-efficacy, and pain in fibromyalgia," Archives of Physical Medicine and Rehabilitation, vol. 87, no. 2, pp. 259-264, 2006.

[29] R. L. Kolotkin and R. D. Crosby, "Psychometric evaluation of the impact of weight on quality of life-lite questionnaire (IWQOL-Lite) in a community sample," Quality of Life Research, vol. 11, no. 2, pp. 157-171, 2002.

[30] M. de Zwaan, K. L. Lancaster, J. E. Mitchell et al., "Healthrelated quality of life in morbidly obese patients: effect of gastric bypass surgery," Obesity Surgery, vol. 12, no. 6, pp. 773$780,2002$.

[31] I. B. Wilson and P. D. Cleary, "Linking clinical variables with health-related quality of life: a conceptual model of patient outcomes," Journal of the American Medical Association, vol. 273, no. 1, pp. 59-65, 1995.

[32] M. R. Maly, P. A. Costigan, and S. J. Olney, "Contribution of psychosocial and mechanical variables to physical performance measures in knee osteoarthritis," Physical Therapy, vol. 85, no. 12, pp. 1318-1328, 2005.

[33] W. J. Gibbons, N. Fruchter, S. Sloan, and R. D. Levy, "Reference values for a multiple repetition 6-minute walk test in healthy adults older than 20 years," Journal of Cardiopulmonary Rehabilitation, vol. 21, no. 2, pp. 87-93, 2001.

[34] J. E. Ware Jr and C. D. Sherbourne, "The MOS 36-item shortform health survey (SF-36). I. Conceptual framework and item selection," Medical Care, vol. 30, no. 6, pp. 473-483, 1992.

[35] E. Finch, D. Brooks, P. W. Stratford, and N. E. Mayo, Physical Rehabilitation Outcome Measures, BC Decker, Hamilton, Ohio, USA, 2002.

[36] W. M. Hopman, T. Towheed, T. Anastassiades et al., "Canadian normative data for the SF-36 health survey. Canadian multicentre osteoporosis study research group," Canadian Medical Association Journal, vol. 163, no. 3, pp. 265-271, 2000.

[37] R. L. Kolotkin, R. D. Crosby, K. D. Kosloski, and G. R. Williams, "Development of a brief measure to assess quality of life in obesity," Obesity Research, vol. 9, no. 2, pp. 102-111, 2001.

[38] R. L. Kolotkin, R. D. Crosby, G. R. Williams, G. G. Hartley, and S. Nicol, "The relationship between health-related quality of life and weight loss," Obesity Research, vol. 9, no. 9, pp. 564571, 2001. 
[39] S. G. Engel, R. D. Crosby, R. L. Kolotkin et al., "Impact of weight loss and regain on quality of life: mirror image or differential effect?" Obesity Research, vol. 11, no. 10, pp. 1207$1213,2003$.

[40] L. Hu and P. M. Bentler, "Cutoff criteria for fit indexes in covariance structure analysis: conventional criteria versus new alternatives," Structural Equation Modeling, vol. 6, no. 1, pp. $1-55,1999$.

[41] K. Schermelleh-Engel, H. Moosbrugger, and H. Muller, "Evaluating the fit of structural equation models: tests of significance and descriptive goodness-of-fit measures," Methods of Physiological Research Online, vol. 8, pp. 23-74, 2003.

[42] R. O. Crapo, R. L. Jensen, M. Hegewald, and D. P. Tashkin, "Arterial blood gas reference values for sea level and an altitude of 1,400 meters," American Journal of Respiratory and Critical Care Medicine, vol. 160, no. 5, part 1, pp. 1525-1531, 1999.

[43] ACSM, ACSM's Guidelines for Exercise Testing and Prescription, Lippincott Williams \& Wilkins, Baltimore, Md, USA, 8th edition, 2010.

[44] K. R. Fontaine and I. Barofsky, "Obesity and health-related quality of life," Obesity Reviews, vol. 2, no. 3, pp. 173-182, 2001. 


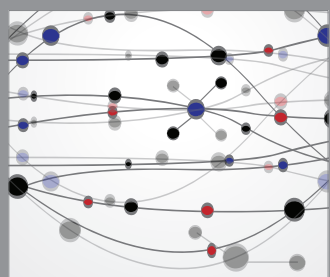

The Scientific World Journal
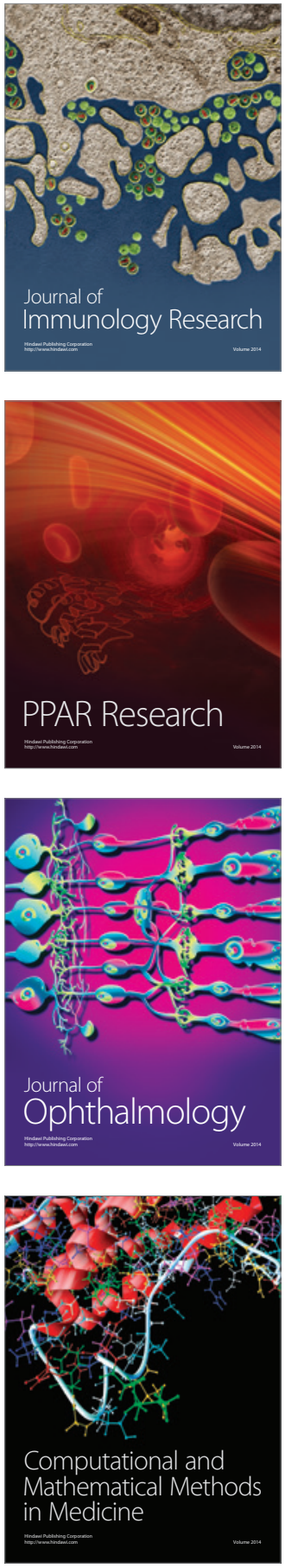

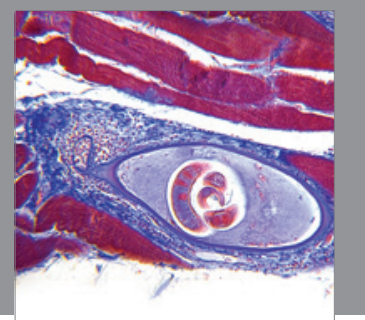

Gastroenterology

Research and Practice
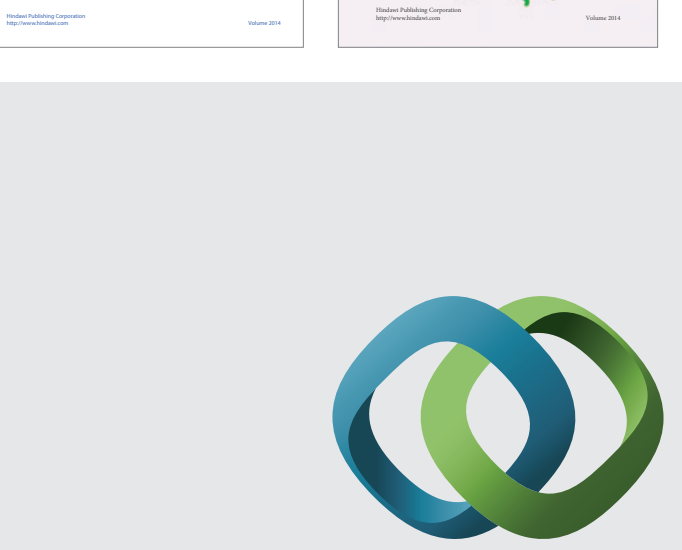

\section{Hindawi}

Submit your manuscripts at

http://www.hindawi.com
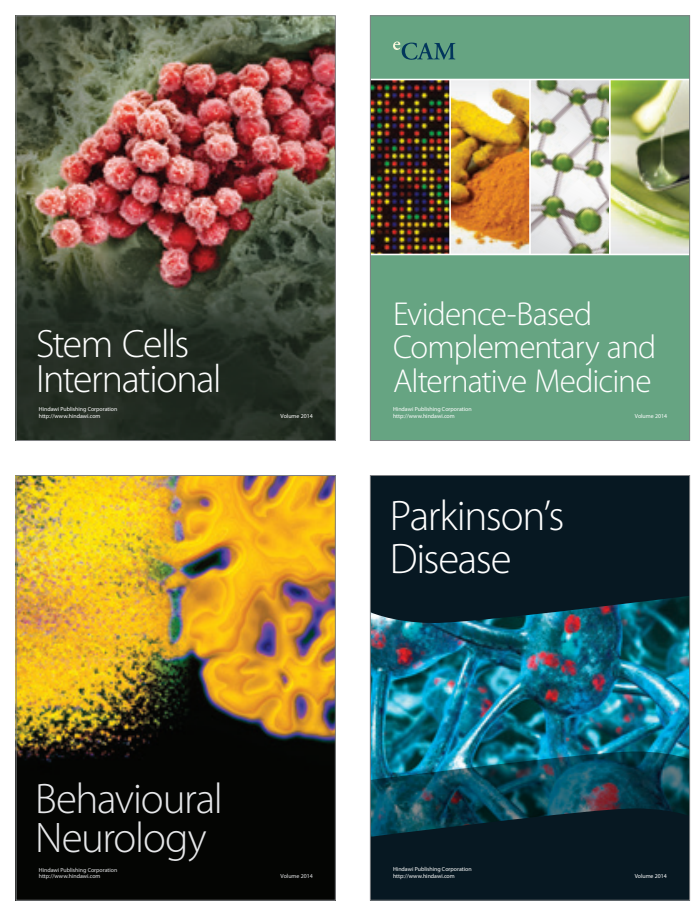

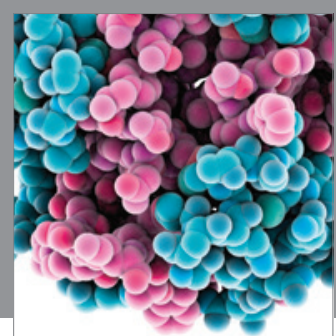

Journal of
Diabetes Research

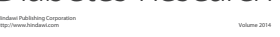

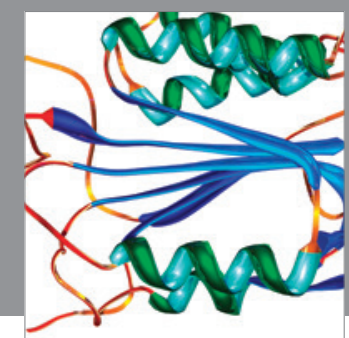

Disease Markers
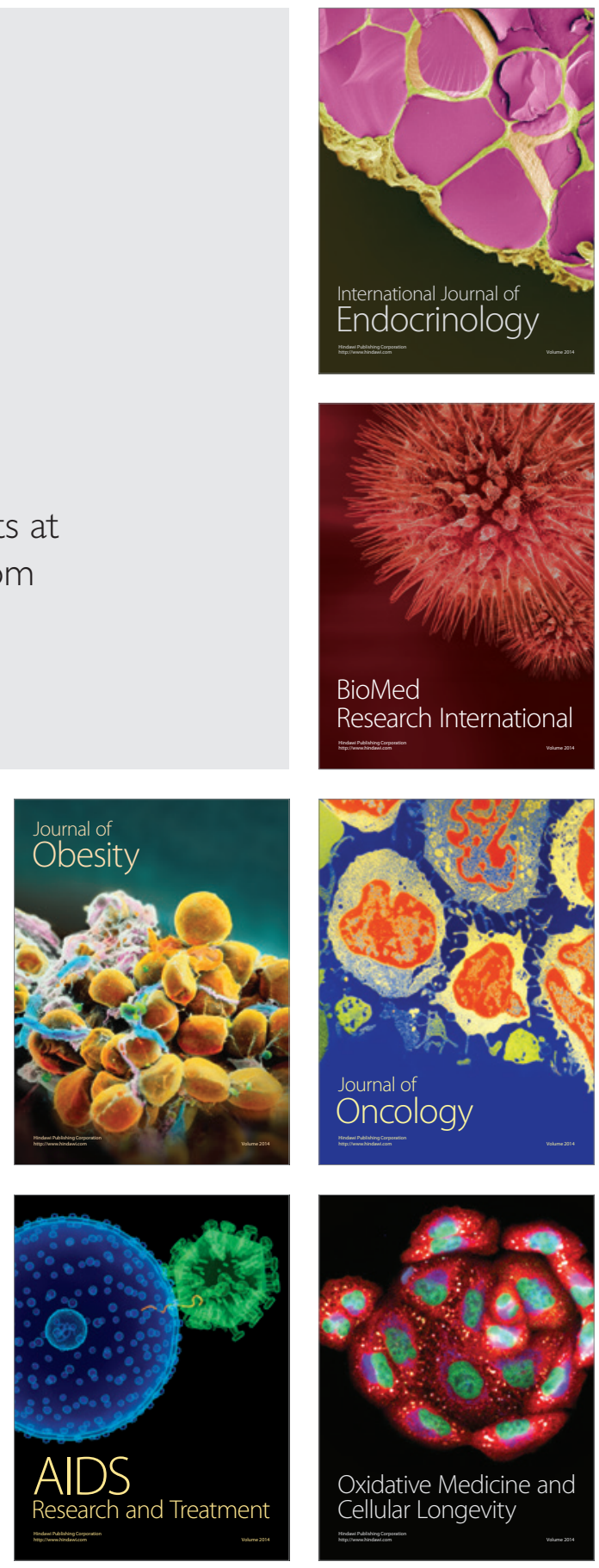